\title{
DISCUSSION
}

\section{A novel elasto-viscoplastic formulation for compression behaviour of clays}

\author{
YIXING YUAN*, ANDREW J. WHITTLE $\dagger$ and PAUL G. JOSEPH $\$$
}

\section{Contribution by P. G. Joseph}

The journal editors are to be thanked for publishing a paper that deals with a 'novel elasto-viscoplastic formulation for compression behaviour of clays' that 'provides a unifying framework that can resolve the long-standing paradox of hypotheses A and B' (Yuan \& Whittle, 2018).

The troubling issues in this paper include the following points.

(a) The authors misinterpret the measurement data of incrementally loaded tests on Osaka Bay mud (OBM) from Watabe et al. (2008) on samples with drainage path lengths of 2, 5, 10 and $20 \mathrm{~cm}$, plotted in Fig. 9(a). The authors claim that 'all specimens share the same strain at EOP, as expected for hypothesis A' and that while the experimental measurements for the 5, 10 and $20 \mathrm{~cm}$ thick specimens are in line with expectations, that of the $2 \mathrm{~cm}$ sample deviates from expectations. Fig. 13 shows these end-of-primary (EOP) points plotted and fit with both linear and logarithmic best-fit lines. The logarithmic line has a better fit than the linear one - that is, exactly in line with hypothesis B; EOP measurements differ with thickness. Additionally, the maximum deviation from the best-fit line is from the $5 \mathrm{~cm}$ thick sample; then too the deviation is only $1.5 \%$ - in other words, there is no real anomaly as the authors suggest with the measurements with the $2 \mathrm{~cm}$ sample. Given material heterogeneity and that the duration of these tests is $24 \mathrm{~h}$, the deviations of the EOP measurements for all the tests from the logarithmic best fit are within the margin of error. Rather than further confirming these data and determining if the root cause empirical observations on the specimen are demonstrative of either $\mathrm{H}(\mathrm{A})$ or $\mathrm{H}(\mathrm{B})$ behaviour, the authors instead offer an 'à la carte approach' where one can model either.

(b) The use of another 'novel' system of relating $\log e$ plotted against $\log \sigma_{\mathrm{v}}^{\prime}$ when all the empirical data support an $e-\log \sigma_{\mathrm{v}}^{\prime}$ relationship as being more accurate, suggesting that deviations from the normal $e-\log \sigma_{\mathrm{v}}^{\prime}$ linear relationship for the limiting compression curve are due to grain crushing or due to consolidation across a very large range of void ratios starting from slurry (see e.g. Butterfield, 1979; Cargill, 1984; Townsend, 1987). Joseph (2017) had derived the conventional $e-\log \sigma_{\mathrm{v}}^{\prime}$ relationship from a simple root cause hypothesis, namely that soil deformation is a Poisson process, while no such physically based derivation exists

\footnotetext{
* Formerly Massachusetts Institute of Technology, Cambridge, MA, USA; now GZA GeoEnvironmental Inc., Norwood, MA, USA (Orcid:0000-0002-3408-0358).

$\dagger$ Edmund K. Turner Professor of Civil \& Environmental Engineering, Massachusetts Institute of Technology, Cambridge, MA, USA.

$\uparrow$ Engineering Solutions, Boxboro, MA, USA.
}

for the novel Pestana and Whittle (1999) $\log e-\log \sigma_{\mathrm{v}}^{\prime}$ relationship.

(c) Equation (4) introduces a 'new state variable representing a strain-rate corresponding to the overall perturbation of the clay assembly'. The authors equate this with 'the thermodynamic concept of granular temperature that describes energy level within a granular assembly that is perturbed from an equilibrium state'. There exists no empirical evidence to support kinetic energy at clay levels; in any case, such kinetic energies likely are controlled by the adsorbed water layers on the clay particles whose viscosity is thought to be a key driver of strain rate. This viscosity does not change with the 'overall perturbation of the clay particle assembly' but does depend on strain rate. In short, the basic tenet of the model that the history of straining has a role in strain-rate behaviour is incorrect. For a given particle, strain-rate effects depend on the static and dynamic coefficients of friction of the particle, the viscous behaviour of its adsorbed water layer and the current strain rate. In this sense, the isotache formulation, which assumes strain-rate effects are uniquely identified by $e$ and $\sigma_{\mathrm{v}}^{\prime}$, is also invalid. Finally, the hypothesis of Taylor (1942) that associates secondary consolidation with 'the disturbance and remoulding effects caused by primary consolidation' has been clearly elaborated in detail in Mesri \& Choi (1985) and Mesri \& Vardhanabhuti (2009).

(d) As with equation (4), the authors' equations (5)-(9) are not based on any physical underlying process. Further, either there is only $\mathrm{H}(\mathrm{A})$ behaviour or $\mathrm{H}(\mathrm{B})$ behaviour, never both, and it is puzzling why the authors want a model that can do both. They do this by an heuristic approach (equation (8)) consisting of tacking on a logarithmically scaling multiplier $\dot{\varepsilon} / \dot{\varepsilon}_{\text {ref }}$ that is raised to a curve-fitted parameter $\beta$ to what is an $\mathrm{H}(\mathrm{A})$ model that in turn must be fitted to obtain results that match the base $\mathrm{H}(\mathrm{A})$ behaviour.

(e) The term 'steady state' in soil mechanics and dynamical systems theory is strictly defined in the paper by Poulos (1981). This strict definition forms the basis of dynamical systems-based soil mechanics (Joseph, 2017) and, like other terms with defined meanings, should be used only when all the conditions that describe the term are satisfied. The authors, however, use the term in an ad hoc manner; for example, 'The steady-state condition closely pertains to the normal consolidation behaviour of clay in a constant rate of strain (CRS) consolidation test.' It does not - the normal consolidation behaviour of clays does not meet the requirements of the steady-state condition, and to use this term casually and incorrectly is to introduce confusion.

( $f$ ) From Fig. 11, the 'new perspectives' that the authors claim resolve the contradictory thickness effects for OBM are $(a)$ not new and $(b)$ do not resolve any contradiction with thickness effects because there is no contradiction. Viscous effects are long known to depend on strain rate; higher strain rates are due to 


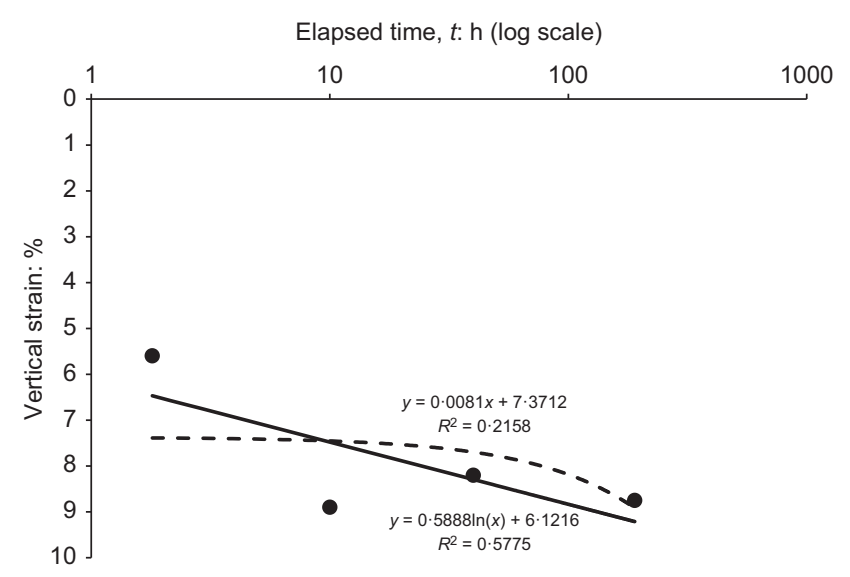

Fig. 13. Replotted OBM data from authors' Fig. 9, showing H(B) behaviour based on best-fit line

shorter drainage paths and result in larger viscous effects. Conversely, longer drainage paths result in very small strain rate effects; the suggestion that field behaviour where drainage paths tend to be long and result in behaviour closer to $\mathrm{H}(\mathrm{A})$ is also not new; see Joseph (2017).

Viscous effects are not the same as creep; they superpose on particle movements and occur due to the strain rate sensitivity of the dynamic and static coefficients of friction and the interparticle fluids, especially the adsorbed layer on the particles as Terzaghi noted as early as 1948 (Terzaghi \& Peck, 1948).

The authors do not model these underlying root cause physical behaviours; their model is but a thumb rule that sheds no new light on the issues involved but, instead, confuses them.

\section{Authors' reply}

The authors acknowledge the discusser's interest in their paper, but believe that most of the 'troubling' findings are due to misunderstandings and misrepresentation of their proposed model. The following items refer to the list of issues raised by the discusser.

(a) The discusser claims that the authors misinterpreted the measured data of interconnected oedometer tests on OBM from Watabe et al. (2008). He has quoted a sentence from the paper out of context. ('All specimens share the same strain at EOP, as expected for hypothesis A.') This sentence is not a final interpretation of the data, but simply part of the authors' investigation to illustrate limitations in the prediction of the measured data using their proposed formulation for the case with $\beta=0$ (where the authors are able to simulate results corresponding to hypothesis A). Indeed, the authors show limitations for this case and also for the case where $\beta=\rho_{\alpha} / \rho_{\mathrm{c}}\left(=C_{\alpha} / C_{\mathrm{c}}\right)$, which reproduces conventional isochrone models. The above simple mistake by the discusser leads to a further series of misunderstandings, as follows.

(i) The discusser proposes an alternative interpretation that entails a logarithmic regression with only four EOP data points in an $\varepsilon-\log t$ plot (discussion Fig. 13). This interpretation is highly questionable, because, first, it relies on a poor fit to the data $\left(R^{2}<0 \cdot 6\right)$, and second, it only uses EOP states and neglects the measured data for the primary consolidation and secondary compression phases.

(ii) Following his interpretation, the discusser asserted, 'There is no real anomaly as the authors suggest with the measurement with $2 \mathrm{~cm}$ sample.' In fact, the outstanding behaviour of the $2 \mathrm{~cm}$ thick specimen of OBM was originally reported by Watabe et al. (2008: p. 557) ('the strain for $\mathrm{H} 2$ is approximately $30 \%$ smaller than that for $\mathrm{H} 5$, $\mathrm{H} 10$ and $\mathrm{H} 20$ at $t / H^{2}=1 \times 10^{2} \mathrm{~min} / \mathrm{cm}^{2}$ in Fig. 23(a)').

(iii) The discusser then claims that the authors offer an à la carte approach where one can model either (hypothesis A or B for OBM clay). This is another misunderstanding. The authors' interpretation consisted of two sets of model evaluations for the OBM clay (Figs 9(a) and 9(c)). However, each evaluation finds limitations in characterising the observed behaviour. In the end, the authors infer that the discrepancy between predictions and measurements may be related to variations in the rate-sensitivity of OBM with strain rate level. Interestingly the discusser seems to agree with the authors' implication in his comments listed as $(c)$ and $(f)$.

(b) The limitations of the conventional $e-\log \sigma_{\mathrm{v}}^{\prime}$ framework have been highlighted in many studies (e.g. Pestana \& Whittle, 1999). For instance, a linearised virgin compression line (VCL) relation in $e-\log \sigma^{\prime}$ space inevitably leads to a negative void ratio at high stress level. This is not physically possible, and highlights a long-standing anomaly in the conventional $e-\log \sigma_{\mathrm{v}}^{\prime}$ relation. This reality is not resolved by the discusser's claim to the contrary.

(c) The discusser appears to misunderstand the physical meaning and role of the new state variable $R_{\mathrm{a}}$ in the authors' model. The internal strain rate, $R_{\mathrm{a}}$, represents the overall perturbation of the clay particle assembly due to historical straining. This representation logically explains the processes of creep or relaxation, as these phenomena are typically observed after the cessation of prior loading or straining in laboratory tests (and also field measurements). Thus, the history of straining can have a role in explaining creep and relaxation behaviour of clay. The discusser's dispute seems implausible, unless he shows evidence that creep or relaxation occurs for clay without any prior loading or straining events. As a state variable, $R_{\mathrm{a}}$ is not meant to represent the viscosity property of clay particles. The authors' model uses material parameters $\beta$ and $\rho_{\alpha}$ to characterise the effect of viscosity. The former corresponds to the rate-sensitivity of the normal consolidation behaviour, whereas the latter controls the relaxation and secondary compression behaviour. The authors' interpretation of OBM clay further implies a variation of rate-sensitivity $\beta$ with strain rate level.

(d) The discusser argues that equations (4)-(9) in the authors' model are not based on any physical underlying process, and later regarded the model as 'a rule of thumb'. On the contrary, the paper under discussion has described in detail the physical meaning of these equations: equation (4) attributes viscoplastic strain rate to the overall perturbation of clay particles represented by the state variable, $R_{\mathrm{a}}$; equation (6) describes the evolution of $R_{\mathrm{a}}$ in terms of two underlying processes: ( $i) R_{\mathrm{a}}$ increases when external straining stimulates the clay particle assembly, and (ii) $R_{\mathrm{a}}$ fades 
with time as clay particles adjust towards a new equilibrium state; equation (5) represents the standard density hardening process; equations (7)-(9) relate the aforementioned underlying process to a range of typical rate-dependent compression behaviour of clay in oedometer and CRS tests. Nevertheless, it is an exaggeration to claim a model as a rule of thumb because of a lack of physical basis at the underlying (micro- or nano-) scale. Indeed, such a claim could apply to most constitutive relations, including the model presented by Joseph (2017).

The discusser questions why the authors developed a model to represent both hypothesis A and hypothesis B. There are two reasons. First, there are extensive, highly credible data that support both hypothesis A (e.g. Mesri, 2001) and hypothesis B (e.g. Leroueil, 2006), and some cases where both occur for a single material (such as OBM; Watabe et al., 2008). These observations highlight the need for models that can represent these different effects of length scaling. Second, in the area of constitutive modelling, there are several well-known models that represent hypothesis B behaviour (isochrones type models), but no formulations that represent behaviour corresponding to hypothesis $\mathrm{A}$. This long-standing deficiency renders an impression that the latter behaviour is unphysical and can only be achieved with radical assumptions, such as excluding creep during primary consolidation. The authors' proposed model demonstrates that both hypothesis $\mathrm{A}$ and $\mathrm{B}$ behaviour can be represented in a unified framework. The model allows concurrent creep to occur throughout consolidation for both hypotheses, and explains their discrepancies in terms of different material rate-sensitivity. In addition, by varying the rate-sensitivity parameter $\beta$, the authors' model offers a full spectrum of material responses between the two limiting cases.

(e) The term 'steady state' in the paper under discussion specifically refers to states within the authors' model where there is no change in the internal strain rate, $R_{\mathrm{a}}$, with time (and has been discussed exclusively in the context of constant rate of strain (CRS) conditions). This behaviour is defined at $\dot{R}_{\mathrm{a}}=0$ in equation (6), and illustrated in Fig. 2. The discusser quoted the authors' term out of context, and compared it with other definitions that mainly relate to the shearing behaviour of clay. Full details of the three-dimensional implementation of the authors' model can be found in Yuan (2016) and will appear in papers submitted for publication.

( $f$ ) While claiming that the authors' perspectives are 'not new' and 'long-known', the discusser has actually endorsed several of the authors' positions. In fact, the authors have offered a new explanation for the contradictory effects of specimen thickness for OBM clay (that differ from explanations by Watabe et al. (2008)). The discusser's claim seems to be a case of hindsight bias.

\section{REFERENCES}

Butterfield, R. (1979). A natural compression law for soils. Géotechnique 29, No. 4, 469-480, https://doi.org/10.1680/geot. 1979.29.4.469.

Cargill, K. W. (1984). Prediction of consolidation of very soft soil. J. Geotech. Engng 110, No. 6, 775-795.

Joseph, P. G. (2017). Dynamical systems-based soil mechanics. Leiden, the Netherlands: CRC Press.

Leroueil, S. (2006). The isotache approach. Where are we 50 years after its development by Professor Šuklje? In Proceedings of the 13th Danube-European conference on geotechnical engineering, vol. 2, pp. 55-88. Ljubljana, Slovenia: Slovenian Geotechnical Society.

Mesri, G. (2001). Primary compression and secondary compression. In Proceedings of soil behavior and soft ground construction, symposia in honor of Charles C. 'Chuck' Ladd (eds J. T. Germaine, T. C. Sheahan and R. V. Whitman), pp. 122-166. Reston, VA, USA: American Society of Civil Engineers.

Mesri, G. \& Choi, Y. K. (1985). The uniqueness of the end-of-primary (EOP) void ratio-effective stress relationship. In Proceedings of the 11th international conference on soil mechanics and foundation engineering (ICSMFE), vol. 2, pp. 587-590. Rotterdam, the Netherlands: Balkema.

Mesri, G. \& Vardhanabhuti, B. (2009). Compression of granular materials. Can. Geotech. J. 46, No. 4, 369-392.

Pestana, J. M. \& Whittle, A. J. (1999). Formulation of a unified constitutive model for clays and sands. Int. J. Numer. Analyt. Methods Geomech. 23, No. 12, 1215-1243.

Poulos, S. G. (1981). The steady state of deformation. J. Geotech. Engng 107, No. 5, 553-562.

Taylor, D. W. (1942). Research on consolidation of clays, Report Serial 82. Cambridge, MA, USA: Department of Civil Engineering, Massachusetts Institute of Technology.

Terzaghi, K. \& Peck, R. B. (1948). Soil mechanics in engineering practice. New York, NY, USA: John Wiley and Sons.

Townsend, F. C. (ed.) (1987). Symposium on consolidation and disposal of phosphatic and other waste clays. Bartow, FL, USA: Florida Institute of Phosphate Research.

Watabe, Y., Udaka, K., Kobayashi, M., Tabata, T. \& Emura, T. (2008). Effects of friction and thickness on long-term consolidation behavior of Osaka Bay clays. Soils Found. 48, No. 4, $547-561$.

Yuan, Y. (2016). A new elasto-viscoplastic model for rate-dependent behavior of clays. $\mathrm{PhD}$ thesis, Massachusetts Institute of Technology, Cambridge, MA, USA.

Yuan, Y. \& Whittle, A. J. (2018). A novel elasto-viscoplastic formulation for compression behaviour of clays. Géotechnique, https://doi.org/10.1680/jgeot.16.P.276. 